1 Fundação Oswaldo Cruz (Fiocruz), Escola Nacional de Saúde Pública Sergio Arouca (Ensp), Centro de Estudos da Saúde do Trabalhador e Ecologia Humana (Cesteh) - Rio de Janeiro (RJ), Brasil.

katreis@ensp.fiocruz.br

2 Fundação Oswaldo Cruz (Fiocruz), Escola Nacional de Saúde Pública Sergio Arouca (Ensp), Centro de Estudos da Saúde do Trabalhador e Ecologia Humana (Cesteh) - Rio de Janeiro (RJ), Brasil. anabraga@ensp.fiocruz.br

3 Fundação Oswaldo Cruz (Fiocruz), Escola Nacional de Saúde Pública Sergio Arouca (Ensp), Centro de Estudos da Saúde do Trabalhador e Ecologia Humana (Cesteh) - Rio de Janeiro (RJ), Brasil.

branirozemberg@uol.com.br

\section{Formação em saúde do trabalhador e saúde ambiental: avaliação de experiência com atores locais}

\author{
Training in workers' and environmental health: experience \\ assessment of local actors
}

Katia Reis de Souza1, Ana Maria Cheble Bahia Braga², Brani Rozemberg 3

RESUMO O presente estudo tem como objetivo analisar a experiência de formação em saúde do trabalhador e saúde ambiental em base territorial local, adotando como matéria principal de interpretação as avaliações dos próprios trabalhadores. Por meio da técnica de análise de conteúdo, chegou-se a duas categorias empíricas de análise, sendo a primeira a interdisciplinaridade e construção coletiva do conhecimento, e a segunda, a intersetorialidade e os saberes advindos da prática. Ao final, constataram-se elementos formativos, de caráter crítico, que contribuem para a emancipação dos atores locais e as ações de políticas públicas integradas.

PALAVRAS-CHAVE Saúde do trabalhador. Saúde ambiental. Educação continuada.

ABSTRACT The study here reported had as objective to analyze the training experience in workers' and environmental health focused on local territory, adopting as interpretation main data assessments issued from the workers themselves. By means of content analysis, we arrived to two empirical categories of analysis. The first is interdisciplinarity and knowledge collective construction, and the second is intersectoriality and skills acquired through practice. At the end, formative elements of critical character were verified, which contribute to the emancipation of local players and actions of integrated public policies.

KEYWORDS Occupational health. Environmental health. Continued education. 


\section{Introdução}

A aproximação teórica e política do campo da saúde do trabalhador com o de saúde ambiental, vem se confirmando como estratégia fundamental, no âmbito da área de saúde coletiva, para conhecer os problemas atinentes à relação entre saúde, trabalho e ambiente no território e intervir de modo a propiciar mudanças nos processos produtivos e na realidade local (PONTES; RIGOTTO, 2014; RIGOTTO, 2003).

A partir da década de 1980 foi crescendo gradativamente a consciência da importância da relação entre os processos produtivos e a saúde das populações trabalhadora e, também, não trabalhadora. No ângulo de compreensão da história, Tambellini e Câmara (1998) enfatizam a ideia de que a consolidação de uma 'nova saúde ambiental' torna-se viável a partir do momento em que a saúde do trabalhador se declara peça de uma relação mais ampla que abrange a produção, o ambiente e a saúde. Tal fato se evidencia nos efeitos adversos notórios advindos de processos produtivos que extrapolam a área geográfica dos empreendimentos, gerando, muitas vezes, situações de risco ambiental que interferem e perpetuam quadros de morbimortalidade. O seu enfrentamento exige um trabalho integrado e participativo, que estimule e acione mecanismos de coordenação intergovernamental das diversas instituições corresponsáveis na esfera local.

Ademais, considera-se que os riscos decorrentes de processos produtivos e tecnologias que ignoram ou desprezam as necessidades de seres humanos e do meio ambiente não devem ser enfrentados somente por especialistas, mas também pela atuação organizada dos trabalhadores e dos cidadãos em geral, na defesa da vida e da democracia (PORTO, 2005; RIGOTTO, 2003).

A valorização do componente social como dimensão importante na área de saúde coletiva ampliou a concepção de ambiente até então prevalente com a incorporação da noção de 'coletivo' (TAMBELLINI; CÂMARA, 1998). No plano teórico e ideológico, trata-se de uma visão de ambiente que valoriza os sujeitos na sua interação com o ambiente, aspecto igualmente essencial na saúde do trabalhador.

Rigotto (2003) defende que a conciliação da saúde do trabalhador com a saúde ambiental pode ser um caminho profícuo, de modo a servir de fundamento às perspectivas mais abrangentes de pesquisa, formação dos profissionais e formulação de políticas públicas. Entretanto, os serviços de saúde do trabalhador e de saúde ambiental, na configuração política da rede pública no âmbito federal, estadual e municipal, encontram-se apartados na sua forma de organização e governança, ou seja, a estrutura burocrática institucional separou esses serviços em setores. As ações que deveriam estar articuladas para enfrentamento dos problemas, em realidade, configuram-se em objetos de políticas públicas específicas.

Na prática, as questões relativas à saúde do trabalhador e saúde ambiental afiguram-se em um conjunto de relações complexas, o que demanda o alargamento do campo disciplinar de análise para incluir categorias críticas de reflexão, ampliando a capacidade de interpretar a realidade para transformá-la. Para tal, os processos formativos de base crítica e dialógica evidenciam-se como estratégias fundamentais, já que contribuem para emancipação dos atores locais de modo a provocar ações políticas, de caráter público, para intervenção qualificada na realidade (souzA; BONFATTI; SANTOS, 2015).

Todavia, sabe-se da carência de processos formativos no âmbito local, sobretudo nas regiões do interior do Brasil, afastadas dos centros onde se localizam os aparelhos formadores. Nesse sentido, é válido mencionar o estudo de Dias et al. (2010), que ressalta a necessidade de capacitação 
das equipes dos Centros de Referência em Saúde do Trabalhador (Cerest) como sendo o maior 'nó crítico' para o pleno desenvolvimento da Rede Nacional de Saúde do Trabalhador (Renast). As autoras evidenciam que as equipes dos Cerest são frequentemente constituídas pela transferência de servidores de outros serviços ou pela designação após aprovação em concursos públicos sem que seja exigida ou prevista formação ou experiência na área. Ramos (2008) afirma que a consolidação da Renast como principal estratégia da Política Nacional de Saúde do Trabalhador para o Sistema Único de Saúde (SUS) requer profissionais com formação na área e esforço interinstitucional de criação de cursos de formação de pós-graduação em saúde do trabalhador no País.

Destarte, o presente estudo tem como objetivo principal avaliar a experiência de formação em saúde do trabalhador e saúde ambiental, ocorrida em base territorial local com os próprios trabalhadores.

\section{Pressuposto teórico}

Este estudo fundamenta-se nos pressupostos do materialismo histórico, especialmente no enfoque da geografia crítica de David Harvey (2013) e Milton Santos (2010). Nessa vertente, a noção de espaço geográfico e, em especial a ideia de lugar e território, ganha importância capital. Para Harvey (2013), à medida que todos os mercados de trabalho estão localizados, dão-se também sobre uma base geográfica local os vínculos de proximidade e solidariedade, sociais e políticos.

Nessa mesma linha de interpretação, Santos (2010) assegura que o papel da proximidade na perspectiva da geografia crítica não se limita a mera definição de distâncias, se relacionando, sobretudo, à complexidade da contiguidade física entre as pessoas em mesma localidade, que estabelecem intensas e ricas relações, podendo suscitar laços de solidariedades e cooperação, mas também conflitos.

Assim, a arena política local torna-se a base fundamental a partir da qual se processa o 'ajuste espacial' (HARVEY, 2013), sendo que o Estado se torna a instituição central e palco de disputa dos interesses de classe. Em resumo, na linha final de defesa dos interesses de frações e classe é o Estado que pode assumir poderes de regulação política. Não obstante, constata-se que o Estado, em suas esferas local, regional ou nacional, muitas vezes segue a agenda das empresas em vez de acompanhar a agenda do trabalho. Por outro lado, observa-se grande interesse das instituições públicas em investir em programas educacionais, o que pode se converter em favor do trabalho e na defesa do ambiente.

A geografia de acumulação do capital e destruição dos ecossistemas locais requer análise cuidadosa da dinâmica de aperfeiçoamento do controle que o capital exerce para sua reprodução. Por conseguinte, Harvey (2013) chama à atenção para a tese segundo a qual a base geopolítica de mudança de qualquer movimento deve ser construída, de fato, no âmbito local. Interpreta-se, portanto, que a formação dos atores institucionais locais pode constituir-se em importante estratégia para superação dos limites do Estado capitalista e defesa da vida.

\section{Metodologia e caracterização da formação em saúde do trabalhador e saúde ambiental}

A experiência de formação sucedeu-se no município de Cantagalo, localizado no interior do estado do Rio de Janeiro, região Centro-Norte fluminense. Trata-se do maior polo cimenteiro do estado e terceiro do País, cujo processo produtivo apresenta elevado 
potencial poluidor nos ambientes interno e externo das fábricas (PINTO JÚNIOR, 2009).

A formação se deu no período de março a junho de 2012 por meio da realização de um curso de pós-graduação intitulado 'Gestão integrada e participativa em saúde, trabalho e ambiente', ministrado nas instalações da Secretaria Municipal de Educação. Cabe destacar que a formação se constituiu, também, em ação estratégica no âmbito de pesquisa de caráter multicêntrico para implantação de ações de vigilância em saúde nas atividades de coprocessamento de resíduos em cimenteiras no Brasil, cujo propósito foi a combinação entre produção de conhecimento e formação humana para a ação no território. A ideia é a de que os processos formativos de caráter crítico podem propiciar a autonomia dos atores locais de modo a desenvolverem programas de vigilância em saúde do trabalhador e saúde ambiental sob a égide da participação social (souzA; BONFATTI; SANTOS, 2015).

O curso foi estruturado em unidades de aprendizagem com carga horária de 180 horas, distribuídas entre encontros presenciais e exercícios de dispersão. Ao final, foi organizado um seminário para apresentação dos planos de ação resultantes da experiência, na forma de trabalhos finais dos alunos. No que concerne à concepção dos planos de ação, adotou-se a perspectiva do planejamento em saúde como ação social (PAIM, 2005). De acordo com esse enfoque, os processos de planejamento devem ser essencialmente participativos e contribuir para a recomposição de práticas institucionais fragmentadas e insuladas, na tentativa de superar a dicotomia entre teoria e prática.

A seleção dos participantes atendeu a critérios específicos de modo a compor um grupo heterogêneo do ponto de vista disciplinar e setorial, e envolveu 25 profissionais. Todos os integrantes pertenciam ao serviço público municipal, sendo oriundos de diversas secretarias. Os alunos gestores em atividade de rotina foram liberados parcialmente para a formação, cujos encontros presenciais ocorreram uma semana a cada mês, além das atividades de campo.

Nessa vertente, presume-se que a formação com grupos de composição mista favoreça a troca de experiência sobre $o$ trabalho, estimulando a criação coletiva e abrindo caminhos a novas abordagens de ação pública. Ressalta-se que a proposta do curso é incentivar a formação de uma rede de gestão pública integrada por setores públicos na esfera local com o objetivo de encontrar soluções às questões relacionadas aos processos produtivos e socioambientais identificadas pelos próprios participantes a partir do cotidiano de trabalho, de forma a valorizar a experiência e o conhecimento prático (ODDONE ET AL., 1986).

No tocante à análise da experiência de formação, tomou-se como base empírica de interpretação os materiais advindos das avaliações dos seus participantes. Adotaram-se duas modalidades de avaliação que valorizam a visão do aluno: oral e escrita. Esta última, um instrumento designado Ficha de Avaliação do Aluno, serviu como fonte principal desta análise e se constituiu, basicamente, de um roteiro de perguntas abertas de modo a permitir a livre expressão de ideias por parte dos participantes.

Nessa perspectiva, considera-se que as práticas de avaliação não se configuram em ações neutras; em verdade, os valores e a visão dos sujeitos envolvidos constituem-se no ponto de partida para analisar a ação. Colocou-se em prática um processo avaliativo de cunho democrático, conforme preconizado pela pedagogia crítica (FREIRE, 1988), contrapondo-se a protocolos de avaliação de caráter rígido e fechado (SAUL, 2008).

No que tange à técnica de análise dos materiais, realizou-se uma tarefa interpretativa pela análise do conteúdo e da enunciação (MINAYO, 2014), selecionando-se 
os excertos por critério de frequência e similaridade. O agrupamento de excertos permitiu a classificação do conteúdo das avaliações. Por conseguinte, destacaram-se ideias que se repetiam formando núcleos temáticos de interpretação, identificando-se aqueles trechos mais marcantes em relação aos objetivos do estudo. Por fim, chegou-se a duas categorias de análise, sendo a primeira a interdisciplinaridade e a construção coletiva do conhecimento, e a segunda, intersetorialidade e os saberes advindos da prática.

O projeto de pesquisa foi aprovado pelo Comitê de Ética em Pesquisa da Escola Nacional de Saúde Pública Sergio Arouca/ Fundação Oswaldo Cruz (Ensp/Fiocruz) sob a inscrição CAAE: 0155.0.031.000-10 e contou com o apoio de financiamento do Edital Inova Ensp/Fiocruz.

\section{Resultados e discussão}

\section{Interdisciplinaridade e construção coletiva do conhecimento}

As respostas dos alunos ressaltaram a ideia de valorização do processo de construção coletiva de conhecimento. No ângulo de compreensão predominante dos participantes do curso, a formação estimulou momentos de fala e escuta por meio da problematização da realidade, agregando os diferentes saberes e experiências.

O que tornou o curso mais interessante do meu ponto de vista foi a oportunidade de aprender com outras profissões. Foram extremamente enriquecedores esses momentos de troca e compartilhamento dos diversos saberes. (Aluno 6).

Ao observar as aulas, aprendi que conteúdo somente não adianta. Se não for debatido com pessoas de diferentes visões, profissões e interesses, não adianta. (Aluno 15).
Do ângulo de compreensão do processo pedagógico, o primeiro tópico levado a termo no processo de formação foi o mapeamento dos problemas ambientais e de saúde no território do município pelos próprios participantes. Embora o problema de maior visibilidade na região fosse a questão das indústrias cimenteiras, também foram definidos consensualmente mais três temas, em torno dos quais se organizaram grupos, gerando, assim, planos de ação diversificados e que podem ser interpretados como um diagnóstico inicial local sobre a saúde, o trabalho e o ambiente, a saber: indústrias cimenteiras; agrotóxicos; fábrica de papel; e a atenção primária e os Agentes Comunitários de Saúde.

Afirma-se que, nas questões que envolvem a temática socioambiental, há dimensões políticas, técnicas e culturais que só serão percebidas e respondidas quando se ultrapassarem as barreiras disciplinares por meio do diálogo coletivo e do planejamento para a ação (CESCO, 2011).

O curso modificou minha percepção sobre a influência do ambiente na saúde do trabalhador, me aproximando mais desta área e modificando a minha prática. (Aluno 2).

Com efeito, outro tópico fundamental da formação foi o diálogo a respeito do vínculo concreto entre produção, ambiente e saúde. Debateu-se a tese marxista de interação metabólica a partir da assertiva de que homens e mulheres, ao se apropriarem da natureza, a transformam e ao transformá-la, transformam a si mesmos (MARX, 2013). Nessa linha de compreensão, afirma-se que o trabalho não é, absolutamente, externo ao homem nem tampouco neutro em relação à saúde. Além do mais, de acordo com tal genealogia teórica, a produção e o trabalho constituem-se em aspectos centrais à análise do ambiente, diferentemente da concepção ecológica clássica, cuja noção de ambiente omite os aspectos ligados à produção e à história 
(TAMBELLINI, 2002). "A liberdade para nos expressarmos e a riqueza dos conteúdos abordados foram as características que mais me agradaram" (Aluno 12).

No transcurso da formação, houve a contextualização dos temas definidos pelos alunos de modo que tudo fosse compreendido como passível de mudança, já que outro importante aspecto teórico do processo de formação foi a compreensão da historicidade das questões atinentes à relação saúde, trabalho e ambiente. Para Freire (1988), o desenvolvimento da consciência crítica no processo educativo propiciará a qualificação na forma de intervir e uma motivação para ação.

Nessa mesma linha de compreensão, Almeida Filho (2005) e Amparo (2013) asseguram que o campo da saúde coletiva requer o desenvolvimento de novos projetos e modelos epistemológicos para a integração curricular, de maneira a provocar mudanças fundamentais na forma de pensar e atuar de seus alunos e professores. De fato, o diálogo foi a pedra angular da formação. Para Fávero (2011) e Freire (1988), o diálogo viabiliza metodologicamente o movimento da práxis: parte-se do vivido e do senso comum para discuti-lo, criticá-lo e ampliá-lo na direção do bom senso para, daí, não só mudar a visão de mundo, mas transformar o mundo concretamente.

\section{Intersetorialidade e os saberes ad- vindos da prática}

Vale ressaltar a estratégia de construção dos conteúdos trabalhados com base na realidade do Município; as diversas áreas de conhecimento; e a oportunidade de crescimento do grupo. Dessa forma, houve um comprometimento dos participantes com a execução dos projetos. (Aluno 4).

$\mathrm{O}$ aspecto destacado na avaliação dos participantes no que se refere à estratégia de formação adotada para articular os conceitos aos problemas reais assevera a importância da noção de território ser incorporada como central aos processos pedagógicos de base local. Tal decisão permite a delimitação e a identificação concreta de situações de risco para a saúde, originários nos processos produtivos e em situações de trabalho, de maneira que as ações de vigilância sejam adequadas às necessidades de saúde dessa população (DIAS ET AL., 2009).

De fato, a intersetorialidade das políticas públicas suscita a articulação de saberes técnicos, quando especialistas passam a integrar agendas coletivas e a compartilhar objetivos comuns focados no território (NASCIMENTO, 2010). $\mathrm{O}$ principal desafio está relacionado à superação da fragmentação dessas políticas por meio da articulação entre os atores que as elaboram e executam. A perspectiva de integração possibilita a mudança de valores e da cultura organizacional das instituições públicas.

Aprendi também que a forma como são abordados determinados temas tem efeitos distintos em cada pessoa devido às diferentes opiniões. Acho que todos aprenderam a respeitar cada vez mais as diferentes opiniões. (Aluno 15).

Akherman et al. (2014) e Dias et al. (2009) afirmam a necessidade de se estimular a cooperação entre atores de diferentes setores da sociedade e a integração das diversas políticas públicas. Nessa mesma direção, Garcia et al. (2014) advogam que a intersetorialidade é operacionalizada por meio da criação de uma rede de compromisso social, estruturada por vínculos e uma 'presença viva', na qual instituições, organizações e pessoas se articulam em torno de uma questão da sociedade em um determinado território.

Outro aspecto de destaque nas respostas dos alunos foi a relação entre o conhecimento científico e os saberes advindos da prática; além do já mencionado enriquecimento mútuo entre diferentes disciplinas e setores de trabalho. 
A troca de conhecimento entre os atores da academia e os que atuam na ponta do serviço. A troca de conhecimento entre as diferentes áreas de saberes e a construção de saberes coletivos... A troca de experiência entre os saberes científicos e o saber de quem está vivenciando o problema. (Aluno 1).

Com efeito, colocou-se em prática um dos pressupostos teórico-metodológicos que está na origem do campo da saúde do trabalhador, qual seja, a produção compartilhada de conhecimento sobre a relação saúde, trabalho e ambiente pelo diálogo entre trabalhadores e pesquisadores (ODDONE ET AL., 1986). De acordo com essa perspectiva, torna-se imperativo o reconhecimento da centralidade da experiência do trabalho e do desenvolvimento de processos pedagógicos que estejam estreitamente ligados ao trabalho como procesSo real (SOUZA; BONFATTI; SANTOS, 2015).

\section{Relatos finais}

A experiência aqui relatada permite afirmar que a formação que adota como referência a própria realidade de trabalho, incentiva a troca de conhecimento e experiência adquiridos no dia a dia da complexidade do território. Decerto, o curso propiciou um ambiente favorável para que esses saberes fossem formalizados numa situação de compartilhamento, possibilitando mudanças no modo de ver e agir a partir da estruturação de planos coletivamente construídos. Em síntese, do ponto de vista do método pedagógico empreendido, de caráter crítico, aspectos da teoria freireana se constituíram elementos centrais da formação, como participação, diálogo, problematização, autonomia, valorização da experiência e crítica coletiva (FREIRE, 1988, 2001).

Além disso, afirmaram-se valores preconizados pelo campo da saúde do trabalhador, como a participação dos trabalhadores das fábricas e das comunidades organizadas no território em todas as etapas das ações e intervenções dos planos de ação.

É digno de nota, ainda, o aspecto alusivo à ativação de rede intergovernamental das instituições corresponsáveis pela saúde do trabalhador e saúde ambiental na esfera local, incluindo o fortalecimento da Renast. Confirmou-se que são o Estado e seus atores os que podem assumir poderes de regulação da política local. Todavia, a identificação de obstáculos e conflitos, sobretudo no que diz respeito à relação entre capital e trabalho, foi parte da formação para consecução dos planos de ação, como, por exemplo, a dificuldade em se efetuar mudança de tecnologias nas fábricas estudadas, o que certamente demanda o envolvimento das organizações dos trabalhadores.

Além do mais, foram recorrentes os relatos a respeito da necessidade do desenvolvimento de trabalhos de campo durante a formação, com a perspectiva de se ampliar o conhecimento de problemas a respeito da saúde, do trabalho e do ambiente no território que não somente aqueles referentes às temáticas eleitas para os planos de ação, ou seja, percebe-se que os alunos demandaram o aprofundamento acerca dos problemas locais. Compreende-se que esse e outros aspectos identificados na avaliação dos alunos deverão ser postos em prática no âmbito do próprio trabalho cotidiano das secretarias, já que os atores locais ganharam autonomia na formação. Contudo, o estímulo a uma postura autônoma e crítica se deu nos limites de uma experiência de formação de curta duração, sendo difícil avaliar mudanças na prática dos participantes.

Houve críticas a respeito do pouco tempo de formação para se aprofundarem alguns temas importantes e, também, para se apreender o estilo de se produzir conhecimento no grupo a partir da apresentação dos temas por especialistas, seguida da crítica e da discussão coletiva. Cabe a 
menção sobre a evasão de um aluno, de formação médica, que alegou não compreender o sentido do método adotado - participação, diálogo, problematização e crítica coletiva - e ter tido dificuldade com o tipo de linguagem predominante.

De todo modo, pode-se registrar como exitoso o aspecto referente à iniciativa de construção da vigilância em saúde local por parte dos próprios atores participantes da formação que criaram um grupo, de caráter interdisciplinar e intersetorial, dando continuidade à proposta do curso com construção de agenda de trabalho comum. Desse grupo, dois integrantes foram convidados para assumir a secretaria de ambiente do Município logo após a formação. Não sabemos afirmar os resultados dessa inserção no âmbito do poder municipal, o que seria motivo de outro estudo. Fato é que o processo formativo incentivou o debate público acerca dos problemas locais alusivos à relação entre saúde, trabalho e ambiente, possibilitando, na prática, a integração entre saúde do trabalhador e saúde ambiental a partir da ativação de elementos da formação que se mostraram atuais e pertinentes, i.e., interdisciplinaridade, intersetorialidade, diálogo e práxis.

\section{Colaboradores}

Katia Reis de Souza trabalhou na concepção, redação e interpretação dos materiais do manuscrito. Ana Maria Cheble Bahia Braga e Brani Rozemberg trabalharam na concepção, revisão crítica e aprovação da versão final do artigo.

\section{Referências}

AKHERMAN, M. et al. Intersetorialidade?

IntersetorialidadeS! Ciência \&t Saúde Coletiva, Rio de

Janeiro, v. 19, n. 11, p. 4291-4300, 2014. Disponível em:

<http://www.scielo.br/pdf/csc/v19n11/1413-8123-

csc-19-11-4291.pdf >. Acesso em: 2 jan. 2017.

ALMEIDA FILHO, N. M. Transdisciplinaridade e o paradigma pós-disciplinar na saúde. Saúde e Sociedade, São Paulo, v. 14, n. 3, p. 30-50, 2005. Disponível em: <http://www.scielo.br/scielo.php?pid=S0104$-12902005000300004 \&$ script $=$ sci_abstract\&tlng=pt $>$. Acesso em: 2 jan. 2017.

AMPARO, L. P. Aprender fazendo: a interdisciplinaridade na formação em saúde coletiva.
Ciência \&t Saúde Coletiva, Rio de Janeiro, v. 18, n.

5, p. 1511-1512, maio 2013. Disponível em: <http:// www.scielo.br/scielo.php?script=sci_arttext\&pid $=$ S1413-81232013000500037>. Acesso em: 2 jan. 2017.

CESCO, S. Interdisciplinaridade e temas socioambientais. Estudos avançados, São Paulo, v. 25, n. 72, p. 327-330, maio/ago. 2011. Disponível em: <http:// www.scielo.br/scielo.php?script=sci_arttext\&pid =S0103-40142011000200026>. Acesso em: 2 jan. 2017.

DIAS, E. C. et al. Construção da RENAST em Minas Gerais: a contribuição dos Centros de Referência em Saúde do Trabalhador (CEREST), 2002-2007. Revista Médica de Minas Gerais, Belo Horizonte, v. 20, n. 2, 
supl. 2, p. 66-74, 2010. Disponível em: <http://rmmg. org/artigo/detalhes/1036>. Acesso em: 2 jan. 2017.

DIAS, E. C. et al. Saúde Ambiental e Saúde do Trabalhador na Atenção Primária à saúde, no SUS: oportunidades e desafios. Ciência \&t Saúde Coletiva, Rio de Janeiro, v. 14, n. 6, p. 2105-2112, 2009. Disponível em: <http://www.scielo.br/scielo.php?pid=S1413$-81232009000600013 \&$ script $=$ sci_abstract\&tlng=pt $>$. Acesso em: 2 jan. 2017.

FÁVERO, O. Paulo Freire: importância e atualidade de sua obra. Revista e-curriculum, São Paulo, v. 7, n. 3, p. 1-8, 2011. Disponível em: <https://revistas.pucsp.br/ index.php/curriculum/article/view/7589>. Acesso em: 2 jan. 2017.

FREIRE, P. Pedagogia da autonomia: saberes necessários à prática educativa. 19. ed. São Paulo: Paz e Terra, 2001.

Pedagogia do oprimido. Rio de Janeiro: Paz e Terra, 1988.

GARCIA, L. M. T. et al. Intersetorialidade na saúde no Brasil no início do século XXI: um retrato das experiências. Saúde em Debate, Rio de Janeiro, v. 38, n. 103, p. 966-980, out./dez. 2014. Disponível em: <http://www.scielo.br/pdf/sdeb/v38n103/0103-1104sdeb-38-103-0966.pdf >. Acesso em: 2 jan. 2017.

HARVEY, D. Os limites do capital. São Paulo: Boitempo. 2013.

MARX, K. O Capital. São Paulo: Boitempo, 2013.

MINAYO, M. C. S. O desafio do conhecimento: pesquisa qualitativa em saúde. São Paulo: Hucitec; Rio de Janeiro: Abrasco, 2014.

NASCIMENTO, S. Reflexões sobre a intersetorialidade entre as políticas públicas. Serviço Social \&t Sociedade, São Paulo, n. 101, p. 95-120, 2010. Disponível em: <http://www.scielo.br/scielo.php?pid=S0101$-66282010000100006 \&$ script $=$ sci_abstract $\&$ tlng $=p t>$. Acesso em: 2 jan. 2017.
ODDONE, I. et al. Ambiente de trabalho: a luta dos trabalhadores pela saúde. São Paulo: Hucitec, 1986.

PAIM, J. S. Planejamento em saúde para não especialistas. In: CAMPO, G. W. S. et al. (Org.). Tratado de saúde coletiva. Rio de Janeiro: Hucitec; Fiocruz, 2005. p. 767-782.

PINTO JÚNIOR, A. G. Condições de trabalho e saúde de trabalhadores na queima de resíduos tóxicos em fornos de cimenteiras de Cantagalo, Estado do Rio de Janeiro. 2009. 138 f. Dissertação (Mestrado em Saúde Pública) Escola Nacional de Saúde Pública, Fundação Oswaldo Cruz, Rio de Janeiro, 2009.

PONTES, A. G. V.; RIGOTTO, R. M. Saúde do Trabalhador e Saúde Ambiental: potencialidades e desafios da articulação entre universidade, SUS e movimentos sociais. Revista Brasileira de Saúde Ocupacional, São Paulo, v. 39, n. 130, p. 161-174, 2014. Disponível em: <http://www.scielo.br/pdf/rbso/v39n130/0303-7657-rbso-39-130-161.pdf>. Acesso em: 2 jan. 2017.

PORTO, M. F. Saúde do trabalhador e o desafio ambiental: contribuições do enfoque ecossocial, da ecologia política e do movimento pela justiça ambiental. Ciência \&t Saúde Coletiva, Rio de Janeiro, v. 10, n. 4, p. 829-839, out./dez. 2005. Disponível em: <http:// www.scielo.br/scielo.php?script=sci_arttext\&pid $=$ S1413-81232005000400008 $>$. Acesso em: 2 jan. 2017.

RAMOS, J. C. L. Especialização em saúde do trabalhador no Brasil: estudo dos cursos no período 1986-2006. 2008. 81 f. Dissertação (Mestrado em Saúde Coletiva)

- Instituto de Saúde Coletiva, Universidade Federal da Bahia, Salvador, 2008

RIGOTTO, R. M. Saúde Ambiental e Saúde dos Trabalhadores: uma aproximação promissora entre o Verde e o Vermelho. Revista Brasileira de Epidemiologia, São Paulo, v. 6, n. 4, p. 388-404, dez. 2003. Disponível em: <http://www.scielo. br/scielo.php?script=sci_arttext\&pid=S1415-790X2003000400013>. Acesso em: 2 jan. 2017.

SANTOS, M. O lugar e o cotidiano. In: SANTOS, B. 
S.; MENESES, M. P. Epistemologias do sul. São Paulo: Cortez, 2010

SAUL, A. M. Referenciais freireanos para a avaliação da aprendizagem. Revista de Educação, Campinas, v. 25, p. 17-25, 2008. Disponível em: <http://periodicos puc-campinas.edu.br/seer/index.php/reveducacao/ article/view/90>. Acesso em: 2 jan. 2017.

SOUZA, K. R.; BONFATTI, R. J.; SANTOS, M. B. M.

Participação social, vigilância em saúde do trabalhador e serviço público. Trabalho, Educação e Saúde, Rio de Janeiro, v. 13, n. 2, p. 261-282, 2015. Disponível em: $<$ http://www.scielo.br/scielo.php?script=sci_arttext\&pi d=S1981-77462015000200261 >. Acesso em: 2 jan. 2017.

TAMBELLINI, A. Desafios teóricos na relação produção, ambiente e saúde, In: PORTO, M. F. S.; FREITAS,
C. M. (Org.). Problemas ambientais e vulnerabilidade: abordagens integradoras para o campo da saúde pública. Rio de Janeiro: Fiocruz, 2002. p. 22-39.

TAMBELLINI, A. T.; CÂMARA, V. M. A temática saúde e ambiente no processo de desenvolvimento do campo da saúde coletiva: aspectos históricos, conceituais e metodológicos. Ciência \&t Saúde Coletiva, Rio de Janeiro, v. 3, n. 2, p. 47-59, 1998. Disponível em: <http://www.scielo.br/scielo.php?pid=S1413$-81231998000200005 \&$ script $=$ sci_abstract\&tlng=pt $>$. Acesso em: 2 jan. 2017.

Recebido para publicação em fevereiro de 2017

Versão final em julho de 2017

Conflito de interesses: inexistente

Suporte financeiro: não houve 